Quim. Nova, Vol. 36, No. 5, 738-747, 2013

\title{
A IMPORTÂNCIA DA LEI DE GAY-LUSSAC PARA A CLASSIFICAÇÃO DOS COMPOSTOS ORGÂNICOS
}

\author{
Tânia de Oliveira Camel* \\ Escola Politécnica de Saúde Joaquim Venâncio, Fundação Oswaldo Cruz, Av. Brasil, 4365, 21040-360 Rio de Janeiro - RJ, Brasil \\ Carlos Alberto Lombardi Filgueiras \\ Departamento de Química, Instituto de Ciências Exatas, Universidade Federal de Minas Gerais, CP 702, 31270-901 Belo Horizonte \\ - MG, Brasil
}

Recebido em 22/4/12; aceito em 8/10/12; publicado na web em 4/4/13

\begin{abstract}
IMPORTANCE OF GAY-LUSSAC'S LAW FOR CLASSIFICATION OF ORGANIC COMPOUNDS. This article shows the genesis of the law of volumes of combining gases, formulated by Gay-Lussac in 1808, and how it allowed the expression of the composition of organic compounds in terms of whole numbers of volumes, thus leading to the first classification of organic compounds, formulated by Dumas and Boullay in 1828. It was from this work that Organic Chemistry began to shed its purely taxonomic nature, analogous to what prevailed in Natural History, and to then develop in a vigorous and continuous process, initiating what may be the most significant historical phenomenon in the History of Chemistry of the nineteenth century.
\end{abstract}

Keywords: Gay-Lussac's law of volumes; constitution formulas; organic classification.

\section{INTRODUÇÃO}

Louis-Joseph Gay-Lussac (1778-1850) formou-se pela École Polytechnique em 22 de novembro de 1800, ingressando logo a seguir na École des Ponts et Chaussées. Hobsbawn se refere a essa instituição como: "A revolução francesa transformou a educação técnica e científica de seu país, principalmente devido à criação da Escola Politécnica (1795) - que pretendia ser uma escola para técnicos de todas as especialidades - e do primeiro esboço da Escola Normal Superior (1794) que seria firmemente estabelecida como parte de uma reforma geral da educação secundária e superior por Napoleão. Também fez renascer a definhante Academia real (1795) e criou, no Museu Nacional de História Natural (1794), o primeiro centro genuíno de pesquisa fora das ciências físicas. A supremacia mundial da ciência francesa durante a maior parte de nosso período (1789-1848) se deveu, sobretudo a estas fundações, notadamente à Politécnica, um turbulento centro do jacobismo e liberalismo que atravessou todo o período pós-napoleônico, e um incomparável criador de grandes matemáticos e físicos". ${ }^{1}$

Criada com a intenção de formar a elite científica do país, seu concurso privilegiava o conhecimento de Matemática e essa forma de ingresso não só impulsionou o estudo dessa disciplina, como fez surgir, em Paris, vários estabelecimentos preparatórios. Gay-Lussac iniciou seus estudos nessa instituição em 27 de dezembro de 1797.

O objetivo dessa escola era a formação de futuros engenheiros civis e militares. O Ministro do Interior dizia, em 1797, que a escola dispensava "uma instrução completa e bastante generalizada para servir de primeiro degrau a todas as especialidades possíveis". ${ }^{2}$ As "especialidades", em questão, eram aquelas nas quais era possível se formar em outras grandes escolas nacionais, como a École d' Artillerie, a École des Mines e a École des Ponts et Chaussées, chamadas de "escolas de especialidades". Segundo Crosland, dois fatores contribuíram para que Gay-Lussac se submetesse ao concurso. O primeiro, de ordem puramente intelectual, refere-se ao fato de ingressar em uma instituição de ensino superior já com prestígio, que selecionava somente por concurso. O segundo de ordem econômica pois, como aluno da Polytechnique, receberia uma bolsa de estudos

*e-mail: camel.tania@gmail.com do Estado. O projeto pedagógico da escola enfatizava que os futuros engenheiros deveriam possuir grande conhecimento das Matemáticas, de Física e de Química. ${ }^{3}$

No inverno de 1800/1801, Gay-Lussac trabalhou como assistente de pesquisa de Claude Louis Berthollet (1748-1822) em Arcueil. De acordo com Crosland, Berthollet foi, sem dúvida, a pessoa que mais influenciou Gay-Lussac: "Sua aprendizagem de Química não se fez sob a direção de Berthollet, mas ao seu lado". ${ }^{4}$ Berthollet e GayLussac constituem o núcleo de origem do grupo que ficou conhecido como Círculo de Arcueil (1801-1817). Em 1807, o grupo de 9 membros publicou o primeiro de três volumes de memórias. Os outros membros eram o matemático Pierre Simon Laplace (1749-1827) e seu discípulo, o físico Jean Baptiste Biot (1774-1862), o naturalista Friedrich Heinrich Alexander von Humboldt (1769-1859), o químico Louis Jacques Thénad (1777-1857), o botânico Augustin Pyrame De Candolle (1778-1841), o mineralogista Hippolyte Victor ColletDescotils e o filho de Berthollet - Amédée Barthélemy Berthollet (1780-1810). Mais tarde, o físico François Jean Dominique Arago (1786-1853), o químico Pierre Louis Dulong (1785-1838) e o engenheiro Etienne-Louis Malus (1775-1812) também fizeram parte do círculo. Em Arcueil, havia um laboratório muito apreciado pelos mais jovens e chance de publicação. Os principais objetivos dessa sociedade eram a troca de informações científicas e o exame crítico dos trabalhos. ${ }^{5}$

A primeira pesquisa importante de Gay-Lussac nesse período foi sobre a expansão térmica dos gases, resultando na memória Sur la dilatation des gaz et des vapeurs, publicado em 1802 nos Annales de Chimie. Gay-Lussac mostrou que outros gases tinham o mesmo comportamento que os gases estudados por Jacques Alexandre César Charles (1746-1823), isto é, se uma amostra de gás é aquecida, mantendo-se a pressão constante, a amostra sofre um aumento de volume proporcional ao aumento da temperatura. Gay-Lussac concluiu também que, partindo do mesmo volume inicial, o aumento de volume era igual para todos os gases, para igual aumento de temperatura. A lei quantitativa da expansão térmica é conhecida como lei de Charles, contudo Charles não determinou o coeficiente de expansão e apontou uma expansão desigual para os gases solúveis. A mesma pesquisa foi realizada por John Dalton (1766-1844), quase simultaneamente, porém seu trabalho foi considerado menos preciso. ${ }^{6}$ 
Em 24 de agosto de 1804, Gay-Lussac, acompanhado por Biot, subiu em um balão de hidrogênio alcançando a altitude de $4000 \mathrm{~m}$. Biot, oriundo também da École Polytechnique, foi professor de Matemática na Universidade de Beauvais em 1797 e de Física-Matemática no Collège de France em 1800. Destacam-se as seguintes áreas da Física na sua investigação: Óptica, Eletricidade e Magnetismo. Verificar se a intensidade magnética da superfície da Terra diminuía com um aumento de altitude e recolher uma amostra do ar em altitude elevada para comparar sua composição com aquela no nível do chão eram os objetivos da pesquisa. Uma segunda subida em balão foi feita em 16 de setembro de 1804. A altitude alcançada foi de $7016 \mathrm{~m}$ acima do nível do mar e nessa ocasião Gay-Lussac foi sozinho, de modo que o peso do balão se reduzisse e este atingisse uma altura maior. A análise química das amostras de ar por ele coletadas mostrou que a composição centesimal dos componentes da atmosfera é constante, independendo da altitude, contrariamente ao que se pensava antes, quando se supunha que os componentes mais pesados (gás carbônico e oxigênio) se concentrariam nas camadas inferiores da atmosfera. ${ }^{7}$

Em março de 1805, Gay-Lussac fez uma viagem de cerca de um ano pela Europa com Humboldt. Nessa ocasião, eles determinaram a proporção em volume em que o oxigênio e o hidrogênio se combinam para formar a água e concluíram que 100 partes de oxigênio em volume se combinam com 200 partes de hidrogênio aproximadamente (o dado experimental correspondente era 199,89). Essa informação era importante para determinar a proporção de oxigênio no ar usando o eudiômetro de Alessandro Giuseppe Antonio Anastasio Volta (1745-1827). ${ }^{8}$ Por esse método, o gás testado, devido à presença de oxigênio, era faiscado com hidrogênio para formar vapor d'água. A contração resultante permitia fazer uma estimativa da proporção de oxigênio na amostra, mas para tal era necessário saber com precisão as proporções relativas em volume em que hidrogênio e oxigênio se combinavam para formar água, e esse era o objetivo do trabalho de Humboldt e Gay-Lussac.

Segundo o próprio Gay-Lussac, transformar as substâncias vegetais e animais, com a ajuda do oxigênio, em água, ácido carbônico e azoto, recolhendo os gases produzidos nessa reação, possibilitaria a análise da matéria orgânica com grande exatidão e simplicidade. ${ }^{9}$ No início de 1806, eles efetuaram uma série de observações sobre o magnetismo terrestre e a memória escrita por ambos sobre o assunto foi apresentada em 8 de setembro de 1806. Juntamente com a pesquisa sobre a dilatação térmica dos gases apresentada em 1802, a memória de 1806 foi decisiva para que Gay-Lussac fosse eleito membro da primeira classe do Institut, isto é para a seção de Física. Estes dois trabalhos destacavam com vantagem a Física e não a Química, o que associado ao seu preparo em Matemática, tornava-o apto para tal seção. ${ }^{10}$ Durante a sua carreira, Gay-Lusac assumiu ora a cátedra de Física, ora a de Química.

Durante 1807, Gay-Lussac realizou uma série de experiências para investigar se havia uma relação geral entre as capacidades térmicas dos gases e suas densidades. Ele mediu a mudança de temperatura de um gás como função de mudanças de densidade produzidas pela livre expansão do gás. Concluiu que o calor perdido pela dilatação é igual ao calor absorvido pela compressão e que a mudança de temperatura era diretamente proporcional à mudança de densidade. Este trabalho tornou-se importante pelas suas consequências para a lei da conservação da energia. ${ }^{11}$

\section{A LEI DE GASES QUE SE COMBINAM - 1808}

No período pós-Lavoisier, durante as três primeiras décadas do século XIX ocorreram mudanças significativas no campo da Química Orgânica, que estão diretamente associadas à lei de Gay-Lussac de 1808 e sua posterior aplicação na pesquisa de produção do éter etílico a partir do álcool segundo a análise gravimétrica de Nicolas-Théodore de Saussure (1767-1845) em 1814, na formulação da teoria das proporções de Jons Jacob Berzelius (1779-1848) em 1813-1814, na nova interpretação da reação citada por Jean-Baptiste André Dumas (1800-1884) e Félix-Polydore Boullay (1806-1835, o filho) em 1827 e, finalmente, na proposta da primeira classificação dos compostos orgânicos por Dumas e Boullay, em 1828, tomando o gás olefiante como o constituinte comum a esses compostos.

Em 31 de dezembro de 1808, Gay-Lussac anunciou em uma reunião da Société Philomathique, ${ }^{12}$ em Paris, a lei de volumes de gases que se combinam: "Darei conhecimento de novas propriedades nos gases, cujos efeitos são regulares, provando que essas substâncias se combinam mantendo uma relação muito simples e que a contração de volume, que elas experimentam pela combinação, segue também uma lei regular". ${ }^{13}$

Na sua memória Sur la combinaison des substances gazeuses, les unes avec les autres, ele citou uma série de exemplos que confirmavam a lei e especificamente se referiu à lei como uma consequência direta do trabalho de 1805 com Humboldt. Crosland defende a tese de que a formulação da lei não é uma consequência direta do trabalho de Gay-Lussac e Humboldt de 1805, mas que provavelmente a descoberta do gás trifluoreto de boro com Thenard, no outono de 1808, tenha levado Gay-Lussac a perceber que o experimento de 1805 era apenas um exemplo de um fenômeno geral. Segundo ele, Thenard e Gay-Lussac ficaram impressionados com a produção de fumaças densas a partir da reação desse novo gás com o ar, e provavelmente compararam este produto com as fumaças produzidas pela reação do amoníaco com o gás ácido muriático e devem ter tentado outras reações do trifluoreto de boro com outros gases, inclusive o amoníaco.

Gay-Lussac considerou ainda as reações da amônia: $\mathrm{NH}^{3}$ com gás muriático: $\mathrm{HCl}$, com ácido carbônico: $\mathrm{CO}^{2}$ e com ácido fluobórico: $\mathrm{BF}^{3} \mathrm{e}$ forneceu as respectivas proporções de combinação em volumes destes ácidos para neutralizar a amônia. Ele ainda exibiu a composição volumétrica da amônia (100 de nitrogênio: 300 de hidrogênio), do gás sulfúrico: $\mathrm{SO}^{3}$ (100 de gás sulfuroso: 50 de gás oxigênio), do ácido carbônico (50 de oxigênio: 100 de óxido carbônico - CO) e dos seguintes óxidos do nitrogênio: óxido de nitrogênio: $\mathrm{N}^{2} \mathrm{O}$, gás nitroso: $\mathrm{NO}$ e ácido nítrico: $\mathrm{NO}^{2}$. Com relação aos óxidos, Gay-Lussac calculou o volume a partir da análise gravimétrica de Davy, transformando a percentagem em peso para volume através da densidade de vapor. ${ }^{14}$

A Tabela 1 reproduz os resultados das análises de Humphry Davy (1778-1829) que foram utilizados por Gay-Lussac. Os dados de Davy se encontram nas duas primeiras colunas e os valores calculados por Gay-Lussac, nas duas últimas colunas. Os mesmos resultados de Davy haviam sido usados por Dalton, em 1803, quando conduziu suas pesquisas com os óxidos do nitrogênio.

Tabela 1. Resultados de Davy e de Gay-Lussac, 1809, p. 215

\begin{tabular}{lccccc}
\hline & $\% \mathrm{~N}$ peso $\%$ O peso & $\% \mathrm{~N}$ vol. & $\%$ O vol. & $\mathrm{N}: \mathrm{O}$ vol. \\
\hline óxido de nitrogênio & 63,3 & 36,7 & 100 & 49,5 & $2: 1$ \\
gás nitroso & 44,05 & 55,95 & 100 & 108,9 & $1: 1$ \\
ácido nítrico & 29,5 & 70,5 & 100 & 204,7 & $1: 2$ \\
\hline
\end{tabular}

Gay-Lussac considerou que as percentagens_em volume revelavam números inteiros exceto para o gás nitroso, entretanto, segundo a análise cuidadosa de Jacques Etienne Bérard (1789-1869), em Arcueil, a proporção em volume é de 100 de nitrogênio: 100 de oxigênio no gás nitroso. Gay-Lussac se baseou nos trabalhos publicados por cientistas como Berthollet, Amédée Berthollet, Biot, Arago, além dos já citados, o que aumentou a credibilidade do assunto exposto. GayLussac lançou mão de alguns resultados de análises gravimétricas e, 
para mostrar a regularidade da lei, converteu a composição em peso para uma razão volumétrica, usando a densidade de vapor determinada por outros pesquisadores. Gay-Lussac se referiu da seguinte forma às proporções observadas nas combinações entre gases: "Vimos, em todos os exemplos precedentes, que a relação de combinação é de 1 a 1,1 a 2 ou de 1 a 3. É interessante destacar que, quando se consideram os pesos, não existe nenhuma relação simples e finita entre os elementos de uma primeira combinação". ${ }^{15}$

No final do artigo de 1809, percebe-se que Gay-Lussac estava em uma posição delicada em relação a Berthollet, seu patrono, amigo e mentor antiatomista. ${ }^{16}$ Berthollet não era simpático à teoria atômica de Dalton e a lei de volumes poderia ser interpretada favoravelmente a essa teoria, que tinha, na lei das proporções definidas, um dos seus pilares. ${ }^{17}$ Gay-Lussac deveria então discutir se os compostos são formados mantendo proporções constantes ou variáveis. Ele conciliou da seguinte maneira as duas concepções: " $O$ Sr. Dalton afirmou que as combinações entre dois corpos acontecem de modo que um átomo de um se une a um átomo do outro, ou a dois, ou a três ou a um número maior. Resulta dessa maneira de conceber as combinações que elas ocorrem mantendo proporções constantes, sem que haja intermediários, e nesse aspecto a teoria do Sr. Dalton se aproxima daquela do Sr. Proust. Os numerosos resultados, que forneço nesse artigo, são também muito favoráveis a essa teoria. O Sr. Berthollet, entretanto, pensa que as combinações ocorrem de maneira contínua e cita como prova os sulfatos ácidos, os vidros, as ligas, as misturas de diversos líquidos, todos compostos muito variáveis nas suas proporções. Inicialmente, é necessário admitir em consonância com o Sr. Berthollet que a ação química se exerce indefinidamente de maneira contínua entre as moléculas dos corpos, qualquer que seja o número delas ou a proporção, e que em geral permite obter compostos em proporções muito variáveis. A ação química se exerce mais poderosamente quando os elementos estão entre si em relações simples ou em proporções múltiplas umas das outras, é então que ela produz compostos que se separam mais facilmente. Conciliam-se dessa maneira as duas opiniões" ${ }^{18}$

Alan J. Rocke (1984) comenta que Gay-Lussac permaneceu fiel a Berthollet, e que considerando a carta de 13 de novembro de 1809, escrita por Thomas Thomson (1773-1852) a Dalton, é possível vislumbrar como os argumentos citados foram recebidos pelos contemporâneos de Gay-Lussac. Thomas Thomson se refere a essa questão da seguinte forma: "o artigo (de Gay-Lussac) é altamente favorável à sua teoria atômica (de Dalton) e é fácil ver que GayLussac a admitia, embora seu respeito por Berthollet lhe induzisse a falar com cautela". ${ }^{19}$

Dalton recusou-se a aceitar a lei de Gay-Lussac, sobretudo porque ela parecia contradizer a sua segunda teoria de mistura de gases, quando se considera a sua relação com a Hipótese de Avogadro. ${ }^{20} \mathrm{~A}$. N. Meldrum aponta que Dalton se entreteve com duas hipóteses para explicar a difusão dos gases. ${ }^{21} \mathrm{~A}$ primeira, formulada entre abril de 1800 e setembro de 1801, não faz qualquer referência ao tamanho das partículas, como é possível observar na citação do próprio Dalton: "Na época em que formulei a teoria da mistura dos gases, eu tinha uma ideia confusa como muitos. Eu supus, na época, que as partículas dos fluidos elásticos eram todas do mesmo tamanho e que um volume de oxigênio continha exatamente tantas partículas quanto o mesmo volume de hidrogênio, ou se não, não tínhamos nenhum dado a partir do qual a questão pudesse ser resolvida". ${ }^{22}$

Ao reconsiderar o assunto, Dalton percebeu que ele não tinha "contemplado o efeito de uma diferença de tamanho nas partículas dos fluidos elásticos. Por tamanho eu entendo a partícula dura no centro juntamente com a atmosfera de calor". Ele refletiu que "se os tamanhos das partículas fossem diferentes e supondo que o calor é o poder de repulsão, nenhum equilíbrio pode ser estabelecido por partículas de tamanhos diferentes pressionando umas as outras". ${ }^{23}$ Sua segunda teoria da atmosfera postulava que os átomos dos diferentes elementos possuíam tamanhos diferentes, então o número de partículas por volume era diferente para cada gás.

O átomo de Dalton é herdeiro em certa medida do atomismo newtoniano descrito na Questão 31 do Opticks, e em outra da teoria tradicional corpuscular do século XVII descendente em última instância das minima aristotélica. Dalton se referia ao átomo da seguinte forma: "nenhum homem pode cortar um átomo". ${ }^{24}$ Dalton identificou os átomos químicos aos átomos físicos. Nesse sentido, pode-se sugerir que Dalton realizou uma síntese entre duas vertentes filosóficas: os átomos de Demócrito e a tradição das minima naturalia, uma vez que seus átomos são indivisíveis, mas também apresentam qualidades que os distinguem.

$\mathrm{O}$ atomismo químico forma sua base conceitual ao atribuir pesos relativos aos elementos e fórmulas moleculares aos compostos. De acordo com esse atomismo existe para cada elemento um único peso atômico, uma unidade quimicamente indivisível, que participa da combinação com unidades semelhantes de outros elementos em números inteiros e pequenos. ${ }^{25}$ Como definiu A. F. Kekulé, em 1867: "A questão se átomos existem ou não [...] pertence antes à metafísica. Na Química nós temos apenas que decidir se a suposição de átomos é uma hipótese adaptável à explicação do fenômeno químico. Como um químico, contudo, considero a suposição de átomos, não apenas aconselhável, mas também absolutamente necessária na Química (...) declaro minha crença na existência de átomos químicos, desde que o termo seja compreendido para denotar aquelas partículas da matéria que não sofrem posterior divisão nas metamorfoses químicas". ${ }^{26}$

Lorenzo Romano Amedeo Carlo Avogadro (1776-1856) e Jöns Jacob Berzelius aceitaram as conclusões de Gay-Lussac. Avogadro desenvolveu as implicações da lei para a relação entre os volumes dos gases e o número de moléculas. ${ }^{27}$ Berzelius adotou o método de volumes para expressar a composição das substâncias nas fórmulas, pois para ele o método não só se apoiava em observações experimentais como era mais coerente.

Gay-Lussac começou, de forma implícita, a adotar certos aspectos do atomismo químico, escolhendo expressar-se, quase exclusivamente, em termos de fórmulas-volume. Usando a lei de volumes de gases que se combinam, a composição em peso podia ser facilmente deduzida pela medida da densidade de vapor dos reagentes. Uma das consequências da sua abordagem volumétrica foi a conversão, que fez em 1815, da análise gravimétrica do álcool e do éter por NicolasThéodore de Saussure.

\section{A ANÁLISE GRAVIMÉTRICA DE THÉODORE DE SAUSSURE - 1814}

Nas análises quantitativas de álcool e éter, de 1807, Théodore de Saussure usou a técnica tradicional da destilação seca e o método da combustão introduzido por Lavoisier e Berthollet. Ele queimava uma amostra de composto orgânico, previamente pesada, adicionando um volume conhecido de oxigênio, transformando o composto orgânico em água e ácido carbônico (atualmente denominado de gás carbônico). Após a queima, os volumes de oxigênio consumido e de ácido carbônico produzido eram determinados. A proporção da água produzida era determinada indiretamente. A partir destes dados, a percentagem em peso de carbono, de hidrogênio e de oxigênio contida no composto orgânico podia ser calculada baseada no conhecimento das densidades dos dois gases simples e da composição quantitativa do ácido carbônico em água. A partir de 1810, Gay-Lussac e Thénard substituíram o oxigênio por clorato de potássio e, em 1815, Gay-Lussac propôs a utilização do óxido de cobre como oxidante. 


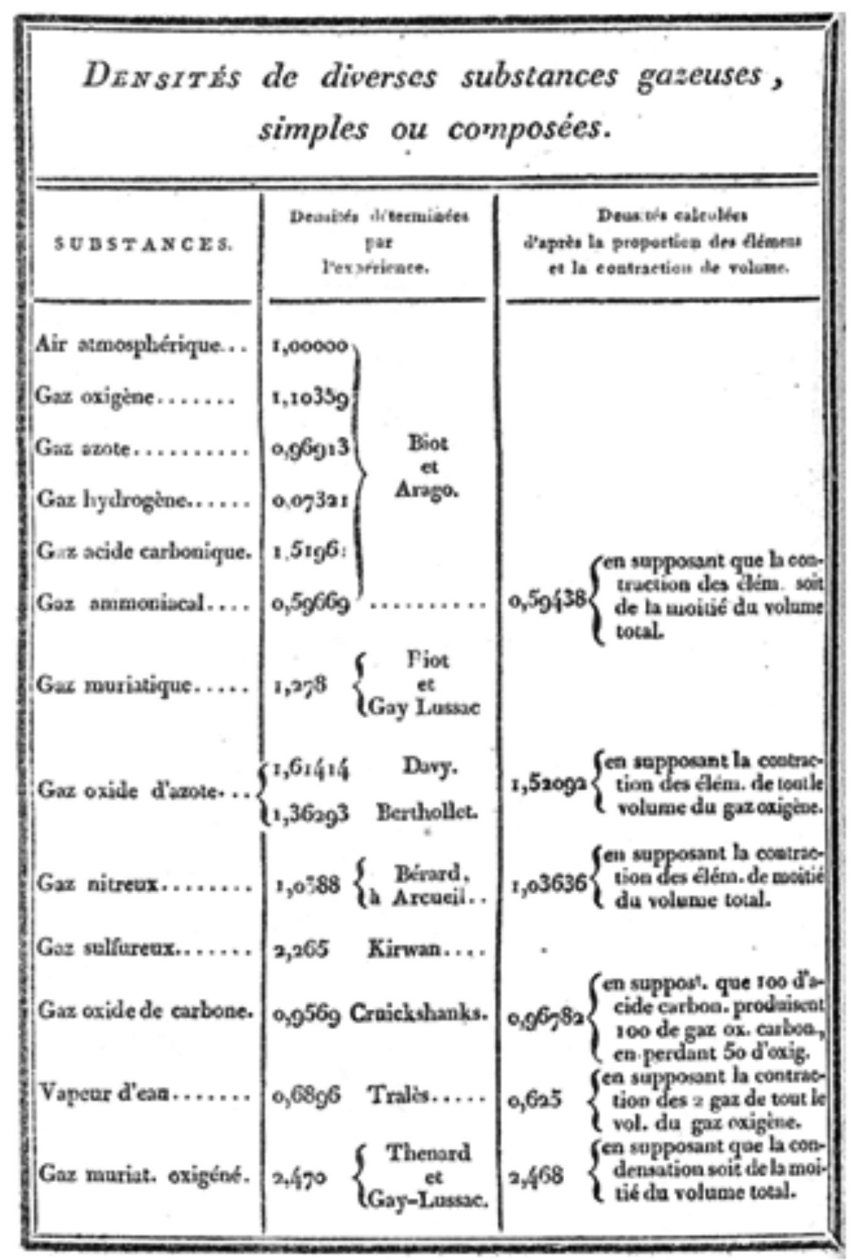

Figura 1. Tabela de densidades de vapor de Gay-Lussac. Sur la combinaison des substances gazeuses, les unes avec les autres, Nouveau Bulletin des Sciences par la Société Philomathique de Paris, Paris, 1808, p. 252

Em 1811, de Saussure determinou a composição do gás olefiante $(\text { eteno })^{28}$ encontrando a proporção em massa hidrogênio:carbono = 1:5,68 neste composto. Posteriormente, em 1814, investigou novamente a reação do álcool comum com ácido sulfúrico para a produção do éter sulfúrico, tentando obter novas informações sobre a reação subjacente à formação do éter. Sua análise sobre os constituintes do álcool mostrou o seguinte resultado: $51,98 \%$ de carbono, $34,32 \%$ de oxigênio e $13,70 \%$ de hidrogênio. De acordo com seu relato do experimento, no artigo de 1814, formava-se um produto gasoso correspondente à água e gás olefiante. Rearranjando as percentagens em peso, concluiu que havia 38,87 de água reduzida a seus elementos ( 38,87 - 34,32 = 4,55 de hidrogênio) e, portanto, 9,15 de hidrogênio em excesso $(13,70-4,55=9,15)$. Este se encontra em relação ao carbono de acordo com a razão $9,15 / 51,98$ o que corresponde exatamente à razão H/C do gás olefiante. No artigo de 1814, Saussure concluiu que o álcool podia ser representado por 38, $87 \%$ de água e 61,13\% de gás olefiante em peso, ou 100 partes de gás olefiante para 63,58 partes de água. Ao repetir o procedimento adotado com o álcool para o éter sulfúrico obteve 80,05\% de gás olefiante e 19,95\% de água. O método empregado nada mais era do que um balanço de massas. Saussure concluiu que: "Uma vez que o álcool é representado por gás olefiante, combinado com uma quantidade de água em peso que é aproximadamente metade da quantidade deste gás - enquanto o éter é composto de gás olefiante unido com água tendo um quarto do peso (do gás olefiante) - e o gás olefiante não contém nenhuma água, a ação do ácido sulfúrico sobre o álcool para formar éter ou gás olefiante torna-se óbvia: em ambos os casos é restrita a retirar a água essencial do álcool". ${ }^{29}$

Gay-Lussac converteu as percentagens em peso de Saussure em razões volumétricas, usando as respectivas densidades: 0,978 para o gás olefiante e 0,625 para o vapor d'água. Expressou então a constituição do álcool em volumes como sendo: 102,5 de gás olefiante e 101,7 de água, isto é, 1 volume de gás olefiante: 1 volume de água. O mesmo foi feito com o éter comum e o resultado obtido sobre a sua constituição em volumes foi de 2 volumes de gás olefiante: 1 volume de água. Dalton, em 1819, também obteve esses resultados. ${ }^{30}$ Para fornecer evidências empíricas, Gay-Lussac comparou a densidade medida do vapor de álcool com a densidade calculada a partir dos seus constituintes gás olefiante e água como se segue: Densidade do álcool $\mathrm{x}$ Volume $=$ densidade do gás olefiante $\mathrm{x}$ Volume + densidade do vapor d'água x Volume, que nada mais é que um balanço de massas baseado na lei da Conservação da Massa. Como nesse caso a proporção em volume é de 1 vol. vapor de álcool à 1 volume gás olefiante +1 volume vapor d'água, resulta que a densidade calculada é dada por: 0,978 $+0,625=1,603$ contra 1,613 para a observada experimentalmente. Gay-Lussac concluiu que "na síntese hipotética do álcool a partir de volumes iguais de gás olefiante e água, ocorre uma condensação de dois volumes em um" e que "o vapor de éter é feito de dois volumes de gás olefiante e um volume de água que se condensam em um". ${ }^{31}$ Este trabalho de Gay-Lussac inspirou Dumas e Boullay na formulação da teoria sobre o éter do ácido sulfúrico em 1827.

Gay-Lussac foi capaz de aplicar seu método de volumes até para sólidos não voláteis, tais como carbono. No seu artigo de 1809, determinou que um volume de oxigênio, quando se combina com o carbono, expande seu volume para dois de óxido carbônico. Como em todas as reações de formação de compostos ocorria contração de volume, Gay-Lussac manteve esta regularidade, supondo que se uma quantidade de carbono pudesse ser vaporizada, ocuparia dois volumes e passou a escrever a fórmula do óxido carbônico como $\mathrm{C}^{2} \mathrm{O}$ e do ácido carbônico como $\mathrm{CO}$, o que corresponderia à seguinte equação química em volumes, caso Gay-Lussac assim tivesse se expressado: $2 \mathrm{C}+1 \mathrm{O}$ à $2 \mathrm{CO}^{1 / 2}$ ou $\mathrm{C}^{2} \mathrm{O} .32$

Cálculo da densidade de vapor do óxido de carbono por Gay-Lussac 1 volume de óxido de carbono $+1 / 2$ vol de oxigênio $\rightarrow 1$ volume de ácido carbônico

Densidade do ácido carbônico determinada experimentalmente $=$ 1,5196; densidade do oxigênio determinada experimentalmente $=1,10359 ;$ densidade do óxido de carbono calculada $=1,5196-$ $1,10359 / 2=0,9672$.

Cálculo da densidade de vapor do carbono por Gay-Lussac ? Volume de carbono +1 volume de oxigênio $\rightarrow 2$ volumes de óxido de carbono

Densidade do carbono calculada: $\mathrm{d}_{\mathrm{c}} \mathrm{V}_{\mathrm{c}}+\mathrm{d}_{\mathrm{o}} \mathrm{V}_{\mathrm{o}}=\mathrm{d}_{\mathrm{co}} \mathrm{V}_{\mathrm{co}} ; \mathrm{d}_{\mathrm{c}} \cdot 2+1,10359$ $=2 \times 0,9672 ; d_{c}=0,41$.

A maioria dos seus artigos publicados entre 1814 e 1816 exibe fórmulas-volume, o que permitia a presença de índices fracionários nestas fórmulas. A especulação de Gay-Lussac sobre o volume correspondente ao vapor de carbono resultou na adoção da densidade de 0,41 para o carbono, o que correspondia a um peso específico de 6 , isto é, metade do seu peso atômico e, consequentemente, o número de átomos de carbono na fórmula foi dobrado.

\section{A TEORIA DAS PROPORÇÕES DE BERZELIUS - 1813/1814}

Em 1813/1814, Berzelius introduziu suas fórmulas químicas, para representar a composição das substâncias no artigo Essay on the 
cause of chemical proportions, and on some circumstances relating to them. ${ }^{33}$ Nesse artigo não só propôs os símbolos químicos conforme usamos até hoje, como estabeleceu que o símbolo expressa sempre um volume da substância. ${ }^{34}$ Nas próprias palavras de Berzelius: "Quando for necessário indicar vários volumes, isto deve ser feito adicionando-se o número de volumes como nos exemplos: ácido sulfúrico: $1 \mathrm{~S}+3 \mathrm{O}$; sulfato de cobre $\mathrm{SO}^{3}+\mathrm{CuO}$ ". ${ }^{35}$

"As fórmulas de Berzelius, após terem sido ignoradas por mais de uma década, se espalharam rapidamente na Química europeia e na norte americana, primeiramente na Química Orgânica" ${ }^{36}$ Durante os anos oitocentos e vinte, alguns químicos como Dumas e Justus von Liebig (1803-1873) empregaram as fórmulas de Berzelius para expressar a composição dos compostos orgânicos, demonstrando como essas poderiam ser produtivas.

Crosland apontou que "nos anos oitocentos e trinta, os símbolos químicos de Berzelius ofereceram uma nova ajuda à Química Orgânica". ${ }^{37}$ Além das possibilidades que tais fórmulas ofereciam para pensar a constituição dos compostos e a interpretação das reações químicas, também permitiam por meio da notação empregada que a composição pudesse ser apreendida em átomos ou volumes dos elementos de um composto.

Berzelius associou aos volumes de Gay_Lussac os pesos relativos invariantes de combinação dos elementos, de modo que sua teoria das proporções é como ele mesmo aludiu no Essai sur les proportions déterminées dans lesquelles se trouvent réunis les éléments de la nature organique de 1814 - uma "teoria corpuscular". Nesse mesmo artigo, Berzelius deduz o volume do carbono como sendo correspondente a um volume de oxigênio: "Um volume de gás oxigênio se combina com a quantidade de carbono necessária para formar o gás óxido de carbono, produzindo o dobro de seu volume de óxido de carbono. $O$ volume adicional é aquele correspondente ao carbono, pois este não pode ser menor do que um volume de oxigênio, uma vez que não se conhece nenhum caso, no qual dois gases se dilatam ao se combinarem. É igualmente improvável que o volume de carbono do óxido de carbono seja superior a um volume igual de oxigênio". ${ }^{38}$

Cálculo da densidade de vapor do carbono por Berzelius

? Volume de Carbono +1 volume de oxigênio $\rightarrow 2$ volumes de óxido de carbono

Densidade do carbono calculada: $\mathrm{d}_{\mathrm{c}} \mathrm{V}_{\mathrm{c}}+\mathrm{d}_{\mathrm{o}} \mathrm{V}_{\mathrm{o}}=\mathrm{d}_{\mathrm{co}} \mathrm{V}_{\mathrm{co}} ; \mathrm{d}_{\mathrm{c}} \cdot 1+1,10359$ $=0,9672 \times 2 ; d_{c}=0,82$ (O dobro do valor calculado por Gay-Lusac, como já mostrado).

Dessa dedução resultou um peso específico para o carbono correspondente ao peso atômico 12 e diferente daquele que GayLussac atribuíra ao carbono, a partir da regularidade observada nas contrações, correspondente a dois volumes de oxigênio.

Berzelius trabalhou com a hipótese de volumes iguais - números iguais de partículas para estabelecer os pesos atômicos relativos a partir das densidades de vapor e pesos relativos dos volumes, portanto, suas partículas têm o mesmo tamanho. ${ }^{39}$

Berzelius, no artigo Essay on the cause of Chemical proportions, de 1813, compara a teoria das proporções em volumes à teoria de átomos e comenta que "aquilo que se denomina volume em uma teoria é o que se denomina átomo em outra". Consequentemente, não há diferença entre as duas teorias, salvo que "uma representa corpos no estado gasoso, enquanto outra representa corpos no estado sólido". Acrescenta que "no atual estágio do conhecimento a teoria dos volumes tem a vantagem de se constituir a partir de dados empíricos enquanto a outra tem apenas a suposição como seu fundamento, entretanto a teoria dos volumes tem a desvantagem de que nem todos os corpos podem existir na forma de gás". As proporções de Berzelius significam unidades mínimas que se combinam entre si em números inteiros ou, ainda, átomo químico como denominou Rocke (1984) ou porção como denominou Klein (2003) e unem o inobservável ao verificável, segundo Berzelius.

A seguir se demonstra o método empregado por Berzelius para determinar a fórmula empírica dos compostos químicos, tomando como exemplo o ácido acético.

Cálculo da fórmula empírica $\mathrm{C}^{4} \mathrm{H}^{6} \mathrm{O}^{3}$ do ácido acético a partir da composição percentual em massa: $\mathrm{C}=47,54 ; \mathrm{H}=5,82$ e $\mathrm{O}=$ 46,54 de acordo com Berzelius, usando as densidades de vapor de cada elemento:

$$
\begin{gathered}
\mathrm{C}=47,54 / 0,8=56 \rightarrow 56 / 42=1,33 \times 3=4 \\
\mathrm{H}=5,82 / 0,07=83 \rightarrow 83 / 42=2 \times 3=6 \\
\mathrm{O}=46,64 / 1,1=42 \rightarrow 42 / 42=1 \times 3=3
\end{gathered}
$$

Cálculo da fórmula empírica $\mathrm{C}^{4} \mathrm{H}^{6} \mathrm{O}^{3}$ do ácido acético a partir da composição percentual em massa: $\mathrm{C}=47,54 ; \mathrm{H}=5,82$ e $\mathrm{O}=46,54 \mathrm{de}$ acordo com Berzelius, usando os pesos atômicos de cada elemento:

$$
\begin{gathered}
\mathrm{C}=47,54 / 12=3,96 \rightarrow 4 \\
\mathrm{H}=5,82 / 1=5,82 \rightarrow 6 \\
\mathrm{O}=46,64 / 16=2,9 \rightarrow 3
\end{gathered}
$$

Como já foi apontado por Klein, a teoria de Berzelius se apoiou na lei de Gay-Lussac, contudo não estava restrita a ela. De acordo com a lei, um volume de uma substância sempre se combina com 1 , 2 ou 3 volumes de outra substância. A teoria de Berzelius permite relações de volumes maiores que as propostas na lei $(1: 1,1: 2$ ou 1:3) e inclui todos os compostos orgânicos. As fórmulas de Berzelius representavam também uma alternativa aos diagramas de Dalton para representar os compostos, porém sem comprometimento explícito com uma teoria atômica na tradição da filosofia natural.

Em 1823, após a morte de Berthollet em 1822, Gay-Lussac tornou-se um atomista, todavia não um atomista daltoniano de acordo com Rocke. ${ }^{40}$ Gay-Lussac, como a maioria dos químicos do século XIX, adotou um atomismo químico que não corresponde ao atomismo de Dalton. Nesse sentido, Gay-Lussac tornou-se um destemido defensor dos conceitos e da terminologia atomista. No artigo de 1823, Sur l'acide des prussiates triples, sobre o ácido ferrociânico, empregou o termo átomo no lugar do termo volume pela primeira vez (Figura 2). ${ }^{41}$

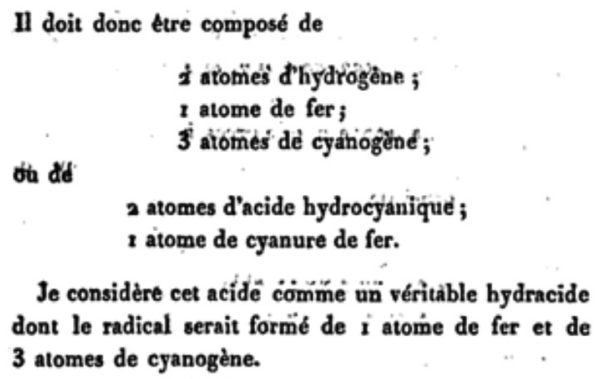

Figura 2. Fotografia do original de Gay-lussac. Sur l'acide des prussiates triples. Annales de Chimie et de Physique 1823, 22, 322

Gay-Lussac também contribuiu para a história da isomeria ao indicar que a análise de Wöhler do cianato de prata era idêntica à análise do fulminato de prata $(\mathrm{AgCNO})$ que ele tinha realizado com o jovem Liebig. Nesta ocasião, comentou que "para explicar suas diferenças, deve-se supor um modo diferente de combinação entre seus elementos". ${ }^{42}$ Há, no artigo de Dumas, Sur quelques points de la Théorie Atomistique, ${ }^{43}$ alguns indícios de que Gay-Lussac foi o único químico contemporâneo de Dumas a aceitar também a consequência imediata da hipótese de Avogadro, isto é, a divisibilidade 
das moléculas elementares, e talvez este fato justifique a mudança de algumas de suas fórmulas nos anos 1820, como, por exemplo, do ácido carbônico de $\mathrm{CO}$ para $\mathrm{CO}^{2} .{ }^{44} \mathrm{~A}$ passagem em questão se encontra muito clara no artigo de Dumas: "O resultado mais imediato desta maneira de ver a questão foi sabiamente discutido por M. Ampère, mas não parece ter sido admitido na prática por nenhum químico, a não ser por M. Gay-Lussac. Ele consiste em considerar as moléculas dos gases simples suscetíveis de uma divisão posterior, divisão esta que acontece no momento da combinação e que varia segundo a natureza do composto". ${ }^{45}$

Em 1827, Gay-Lussac e Dulong se reportaram favoravelmente à Academia das Ciências sobre este artigo de Dumas e não fizeram nenhuma crítica às afirmativas do autor. Segundo Rocke, no prefácio do seu relatório, eles fizeram uma clara distinção entre o atomismo físico, considerado por eles especulativo, e o atomismo químico, verificado adequadamente. Eles recomendavam dois métodos à tarefa de determinar as fórmulas moleculares: a lei de volumes, que chamavam de "uma confirmação evidente da hipótese de Dalton", quando os constituintes eram gases e a lei de Dulong e Petit, quando eram sólidos. ${ }^{46} \mathrm{~A}$ aparente mudança de Gay-Lussac, em torno de 1823 , parece estar relacionada com a morte de Berthollet e pode representar apenas a exteriorização de convicções anteriores.

\section{A FORMAÇÃO DO ÉTER POR DUMAS E BOULLAY - 1827}

Segundo o artigo de 1827, de Dumas e Polydore Boullay, Antoine François de Fourcroy (1755-1809) e Louis Nicolas Vauquelin (17631829) já haviam estabelecido que o ácido sulfúrico, quando colocado em contato com o álcool, levava à formação do éter pela retirada de água do álcool, entretanto ao final do experimento, quando o álcool já estava em menor quantidade e a temperatura mais elevada, uma nova reação ocorria com formação de ácido sulfuroso e óleo doce de vinho. ${ }^{47}$

As observações feitas por Hyacinthe Dabit (1764-1808), de que durante a eterificação formava-se um ácido, foram investigadas pelos farmacêuticos Heinrich August Vogel (1778-1867) e Friedrich W. A. Sertürner (1783-1841), e por Gay-Lussac, que repetiram o experimento e confirmaram que um produto, além do éter comum, se formava na reação do álcool com o ácido sulfúrico. Com a descoberta do acido sulfo-vínico e do óleo doce de vinho, ambos vistos como produtos da reação, tornou-se evidente que o processo de eterificação não era tão simples que pudesse ser explicado somente em termos da desidratação do álcool..$^{48}$

Em 1827, Dumas e Polydore Boullay retomaram a questão da formação do éter. Segundo eles, "as transformações tão variadas que o álcool sofre, através da ação do ácido sulfúrico concentrado em diferentes doses, oferecem um dos assuntos mais curiosos da Química Orgânica". ${ }^{49}$

Dumas e Boullay confirmaram os resultados de Saussure e de Gay-Lussac sobre o álcool e o éter e expressaram a composição do éter em um modelo de constituição binária como sendo: 2 de gás olefiante: $1 / 2$ de água. No artigo de 1827, Mémoire sur la formation de l'ether sulfurique, ao representarem a reação correspondente à formação do éter, ao invés do álcool, mostraram apenas seu constituinte imediato, o gás olefiante $\mathrm{C}^{2} \mathrm{H}^{2}$, como se pode observar na Figura 3 correspondente ao final do artigo de $1827 .{ }^{50}$ Eles expressaram a composição do álcool e do éter em função do gás olefiante. O álcool não era mais um constituinte do éter, uma vez que tanto o álcool quanto o éter foram representados pelos mesmos constituintes imediatos: o gás olefiante $-\mathrm{C}^{2} \mathrm{H}^{2}$ e a água - H·H. ${ }^{51}$ A diferença entre as duas substâncias se restringia apenas à quantidade de água.

Dumas expressou a composição do álcool no sistema de dois volumes, no qual a fórmula $\mathrm{H}^{2} \mathrm{O}$ corresponde a dois volumes, e a de

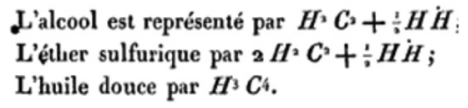

Figura 3. Fotografia do original de Dumas e Boullay de 1827. Dumas, J.-B.; Boullay, P.; Mémoire sur la formation de l'ether sulfurique. Annales de Chimie et de Physique 1827, 36, 309, em http//www.iris.univ-lille1.fr, acessada em Janeiro 2010

$\mathrm{C}^{2} \mathrm{H}^{2}$ a um volume, de acordo, portanto, com a análise de Gay-Lussac de 1 volume de gás olefiante: 1 volume de água. A fórmula de constituição do éter também foi representada no mesmo sistema, e de acordo com Gay-Lussac de 2 volumes de gás olefiante: 1 volume de água.

Dumas e Boullay foram capazes de manter a teoria do éter, mostrando que o éter e o ácido sulfo-vínico eram produtos de duas reações diferentes que ocorriam simultaneamente entre o álcool e o ácido sulfúrico e que o óleo doce era um subproduto do ácido sulfo-vínico. Além do artigo Mémoire sur la formation de l'ether sulfurique de 1827, Dumas publicou, em 1828, o Mémoire sur les ethers composés. É possível perceber que o germe de suas ideias posteriores sobre a classificação química dos compostos orgânicos, de acordo com o sistema de constituição binária, já está presente nos dois artigos.

A distinção entre duas reações simultâneas e independentes, no primeiro período do experimento, oferecia uma solução para a questão colocada em 1820, isto é, de explicar a formação simultânea do ácido sulfo-vínico juntamente com o éter. Para que esta afirmativa fosse plausível, Dumas e Boullay formularam as duas reações em termos de balanço de massa em um modelo interpretativo da reação, partindo dos reagentes álcool e ácido sulfúrico por dois caminhos distintos. Em uma das reações, o éter era obtido e na outra, o ácido e a água. O ácido sulfo-vínico, por sua vez, poderia ainda se transformar em óleo doce de vinho e ácido hipo-sulfúrico.

\section{OS ÉTERES COMPOSTOS DE DUMAS E BOULLAY - 1828}

No artigo seguinte, Mémoire sur les ethers composés, Dumas examinou os éteres nítrico, acético, benzoico e oxálico. Para os quatro éteres, Dumas expressou a composição em massa e em volumes dos seus elementos constituintes: carbono, hidrogênio e oxigênio.

$\mathrm{Na}$ análise do éter do ácido acético, ${ }^{52}$ por exemplo, a composição obtida foi $54,82 \%$ de carbono, $36,425 \%$ de oxigênio e $8,755 \%$ de hidrogênio. Este resultado foi transformado em volumes teóricos pela divisão dos pesos combinados expressos em percentagem em massa pela densidade dos elementos no estado gasoso. As densidades do hidrogênio e do oxigênio foram obtidas da tabela de densidade de vapor de Gay-Lussac sendo, respectivamente, 0,07 e 1,1. A densidade do carbono utilizada foi 0,41 .

A composição em volume encontrada foi 16 volumes de C:16 volumes de $\mathrm{H}: 4$ volumes de O. É interessante ressaltar que expressar a proporção em volumes com números inteiros e grandes não era usual e a dita composição poderia ser expressa como 4:4:1. Dumas a usou porque a relação 16:16:4 era adequada para expressar a composição do éter do ácido acético em uma construção binária. ${ }^{53}$ Dumas e Boullay representavam, portanto, a composição do éter do ácido acético pelo modelo de fórmula de constituição binária como éter + ácido acético: $\mathrm{H}^{10} \mathrm{C}^{8} \mathrm{O}+\mathrm{H}^{6} \mathrm{C}^{8} \mathrm{O}^{3},{ }^{54}$ como se pode observar no fragmento do texto original de 1828, na Figura 4.

Um tipo de verificação comum era o confronto entre a densidade de vapor da substância determinada experimentalmente e a densidade de vapor teórica da substância, calculada a partir das densidades de vapor e da composição em volumes de cada constituinte. Como se pode observar na citação de 1828: "Determinamos com muita atenção a densidade de vapor dos quatro éteres precipitados pelo método do Senhor Gay-Lussac. Encontramos 2,627 para o éter nítrico; 3,067 


\section{MÉmo IRE' sur les Ethers composés.}

Par MM. J. Domas et P. Boollay fils.

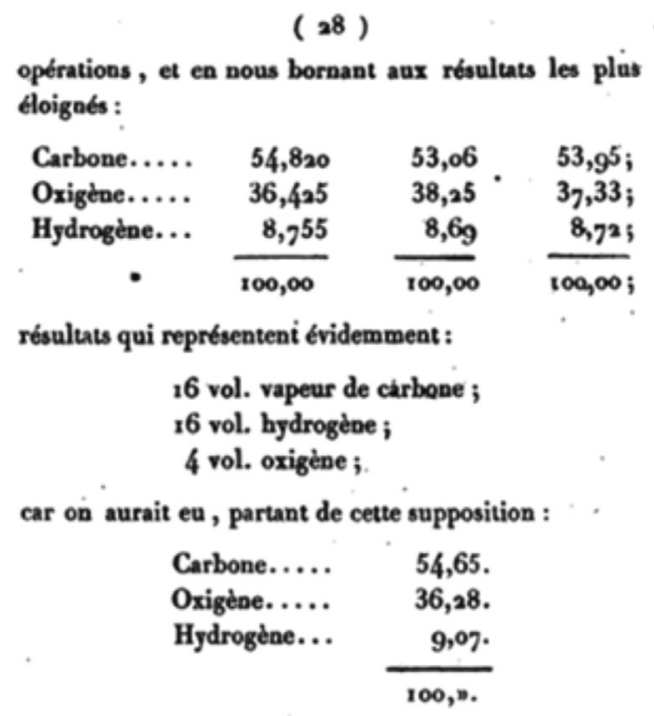

L'éther acétique peut donc être représenté par un atome d'éther sulfurique $\mathrm{H}^{* \bullet} \mathrm{C}^{s} \mathrm{O}$ et un atome d'acide acétique $\mathrm{H}^{6} \mathrm{C}^{5} \mathrm{O}^{3}$.

On remarquera quel'écher acétique renferme 54 p. 100 de carbone, tandis que l'alcool n'en contient que 52 ; et l'acide acétique 49 an plus.

Figura 4. Fotografia do original de Dumas e Boullay de 1828

para o éter acético; 5,409 para o éter benzoico e 5,042 para o ácido oxálico". ${ }^{5}$

A fórmula do éter sulfúrico $\mathrm{H}^{10} \mathrm{C}^{8} \mathrm{O}$, no artigo de 1828 , foi obtida a partir do modelo de fórmula de dois volumes, com o qual Dumas e Boullay haviam representado, em 1827, esta mesma substância $2 \mathrm{H}^{2} \mathrm{C}^{2}+1 / 2 \mathrm{H}^{2} \mathrm{O}$, por simples manipulação, isto é, bastava reunir as fórmulas parciais em um só grupo e multiplicá-lo por 2: $\left(\mathrm{H}^{5} \mathrm{C}^{4} \mathrm{O}^{1 / 2}\right) \mathrm{x}$ 2 à $\mathrm{H}^{10} \mathrm{C}^{8} \mathrm{O}$. Esse modelo de fórmula, $\mathrm{H}^{10} \mathrm{C}^{8} \mathrm{O}$, não se referia mais a 2 volumes como o modelo anterior, mas a 4 volumes da substância. Esta transformação era necessária para tornar a fórmula do éter sulfúrico uma fórmula parcial no modelo de constituição binária do éter do ácido acético, que representasse os resultados analíticos e contivesse a fórmula "berzeliana" aceita para o ácido acético. ${ }^{53}$ No artigo de 1828 , Dumas exibiu a composição de todos os éteres examinados em função do éter sulfúrico e do respectivo ácido em fórmulas de 4 volumes.

Em um modelo de constituição binária, a fórmula do éter sulfúrico era escrita como $\mathrm{H}^{8} \mathrm{C}^{8}+\mathrm{H}^{2} \mathrm{O}$. A fórmula $\mathrm{H}^{10} \mathrm{C}^{8} \mathrm{O}+\mathrm{H}^{6} \mathrm{C}^{8} \mathrm{O}^{3}$ era então transformada em $\mathrm{H}^{8} \mathrm{C}^{8}+\mathrm{H}^{2} \mathrm{O}+\mathrm{H}^{6} \mathrm{C}^{8} \mathrm{O}^{3}$. Dumas e Boullay interpretavam a fórmula parcial $\mathrm{H}^{2} \mathrm{O}$ como um símbolo para água de cristalização como se pode apreender de sua notação, estabelecendo uma analogia com os sais de amônio. Finalmente, a fórmula de 4 volumes $\mathrm{H}^{8} \mathrm{C}^{8}$ devia ser convertida para $4 \mathrm{C}^{2} \mathrm{H}^{2} \mathrm{e}$, consequentemente, o modelo de fórmula de constituição para o éter do ácido acético seria $4 \mathrm{C}^{2} \mathrm{H}^{2}+\mathrm{H}^{6} \mathrm{C}^{8} \mathrm{O}^{3}+\mathrm{H}^{2} \mathrm{O} .{ }^{56}$

De acordo com a visão dominante, Dumas manteve o nome éter para todos os produtos das reações entre o álcool e um ácido qualquer. Havia três tipos de produtos conhecidos que podiam ser formados por este tipo de reação, dependendo do tipo de ácido empregado: o éter sulfúrico quando o ácido empregado era o sulfúrico e, neste grupo, Dumas incluiu também o produto da reação entre o álcool e o ácido fosfórico e entre o álcool e o ácido arsênico, outros éteres com os hidrácidos e um terceiro grupo obtido quando se usavam outros ácidos oxigenados. Esta classificação é apenas uma extensão da classificação feita por Pierre-François-Guillaume Boullay (17771869, o pai) no período de 1807 a 1811. Na decomposição dos éteres dos dois primeiros grupos, o gás olefiante realmente se formava, o que fornecia algum suporte empírico para expressar a composição destes compostos em termos de gás olefiante. Com o terceiro grupo, entretanto, este produto não era observado. De acordo com Thenard, em 1824, o terceiro grupo revelou-se, experimentalmente, composto de álcool e ácido, devendo ser considerado como um grupo à parte. ${ }^{57}$

$\mathrm{Na}$ época, questionava-se sobre o mecanismo das reações químicas, isto é, como ocorriam, se os produtos da reação já estavam presentes nos reagentes e eram libertados durante a reação ou se a redistribuição dos constituintes ocorria durante a reação, dando origem a novas substâncias. Thenard já havia questionado se um éter, sendo um produto da reação entre o álcool e o ácido muriático, era composto por dois "radicais complexos", correspondentes ao ácido e ao álcool respectivamente, ou se a redistribuição dos constituintes ocorria durante o processo de eterificação.

Todos os éteres da memória Sur les ethers composés têm a sua constituição, posteriormente, rearranjada para $\mathrm{C}^{2} \mathrm{H}^{2}$ como se pode observar na tabela de comparação das combinações do gás olefiante com aquelas da amônia no final do artigo. O grupo $\mathrm{C}^{2} \mathrm{H}^{2}$ é um constituinte de todas as substâncias descritas na tabela e está associado ao segundo constituinte variável, que é o responsável pelas propriedades diferentes dessas substâncias.

Este rearranjo de fórmulas é muito comum nos artigos de Dumas e não havia nenhuma restrição a este exercício algébrico, visto que as fórmulas não tinham o significado físico atribuído a elas posteriormente. Dumas e Boullay concluíram que: "os ácidos oxigenados formam, ao contrário (dos hidrácidos), éteres hidratados, isto é, combinações de gás olefiante, de ácido e de água". ${ }^{58}$

O que no primeiro momento foi apresentado como uma conclusão indutiva revela-se como uma teoria no sentido mais amplo, na qual o modelo da fórmula de constituição tinha um efeito retroativo na chamada fórmula empírica. A afirmativa de Dumas e Boullay de que os éteres eram compostos binários contendo o radical hidrogênio bicarburetado - $\mathrm{C}^{2} \mathrm{H}^{2}$ - está apoiada, sobretudo, na "Química no papel”, isto é, em uma concepção prévia de uma constituição binária. $\mathrm{O}$ ato de modelar a constituição dos compostos orgânicos permitiu a sua posterior classificação. ${ }^{59}$

Neste mesmo artigo de 1828, Dumas e Polydore Boullay propuseram a primeira tentativa de uma nova classificação das espécies orgânicas. Esta classificação foi baseada na composição e, sobretudo, na constituição dos compostos orgânicos, isto é, no grupo abstrato de seus elementos constituintes, seus constituintes imediatos. O critério importante na classificação foi o de reunir todos os compostos que partilhavam a mesma constituição binária e aquele de que todos fossem diretamente compostos de hidrogênio, oxigênio e carbono. O grupo comum dessa nova classe de compostos binários era o gás olefiante. As diferenças entre as espécies eram explicadas pelas diferenças no segundo constituinte.

As origens desta classificação se encontram nos trabalhos anteriores de Saussure e Gay-Lussac sobre a constituição binária do álcool e do éter e de Michel Eugène Chevreul (1786-1889) sobre a constituição binária das gorduras. Thomas Thomson (1773-1852) no seu System of Chemistry de 1817 se refere à constituição binária do álcool e do éter por Saussure. No mesmo livro, o éter do ácido muriático também tem sua constituição expressa em termos de gás olefiante e gás ácido muriático. ${ }^{60} \mathrm{~A}$ descoberta de isômeros para muitos compostos orgânicos fez com que apenas a composição não fosse suficiente para caracterizar esses compostos. O isomerismo e o isomorfismo indicavam que a constituição era um aspecto determinante das propriedades 
de um composto, o que era contemplado pelos possíveis arranjos dos constituintes elementares em constituintes imediatos na fórmula de constituição binária. ${ }^{61}$

Dumas e Boullay aumentaram a plausibilidade da analogia implícita entre a constituição dos compostos orgânicos e inorgânicos pela construção de uma analogia mais específica entre a nova classe e uma classe de compostos inorgânicos: os sais de amônio. Segundo N. W. Fisher, "a tabela representa a primeira tentativa de uma classificação química analógica verdadeira. Eles consideravam os sais de amônia como compostos de amônia e outro grupo (normalmente ácido), e a série etil como compostos dos mesmos grupos com o gás olefiante. Eles organizaram uma tabela comparativa das duas séries, e concluíram que a analogia era ainda mais profunda que a semelhança de constituição", ${ }^{62}$ o que se pode ilustrar com a seguinte citação: "Hidrogênio bicarburetado (gás olefiante) desempenha o papel de um álcali poderoso, com uma capacidade de saturação igual àquela da amônia, e tomaria parte em todas as reações, nas quais a amônia toma se fosse solúvel em água". ${ }^{63}$ Cumpre observar que nas fórmulas explícitas na tabela, a separação da fórmula $\mathrm{H}^{2} \mathrm{O}$ para a água, foi interpretada por eles com água de cristalização e, portanto, com significado químico. Conclui-se que na memória de 1828, Dumas e Boullay sugerem que todas essas substâncias contêm o gás olefiante.

$\mathrm{Na}$ tabela exibida na Figura 5, $\mathrm{C}^{2} \mathrm{H}^{2}$ e $\mathrm{AzH}^{3},{ }^{64}$ referem-se aos constituintes partilhados por todos os compostos da tabela, respectivamente, gás olefiante para um volume e amônia para dois volumes. A tabela inclui uma substância hipotética, o ácido oxalovínico, que até então não tinha sido isolada experimentalmente, mas que era de possível existência, de acordo com o esquema classificatório. Trata-se, portanto, de um esquema de rearranjo de fórmulas que possibilitava fazer previsões.

\begin{tabular}{|c|c|c|c|}
\hline KOM DU COMPOSE. & BASE. & Actios. & EAV. \\
\hline 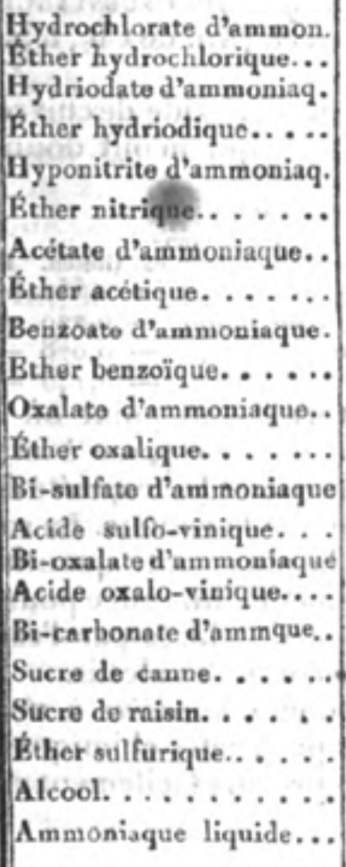 & 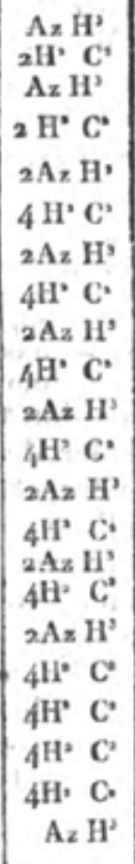 & 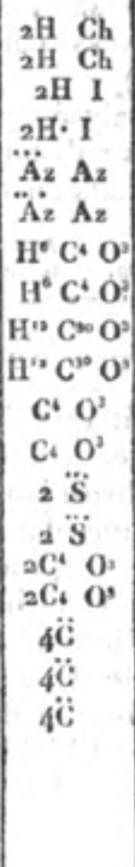 & $\begin{array}{l} \\
\\
\text { H H } \\
\text { H H } \\
\text { H H } \\
\text { H. H } \\
\text { H H } \\
\text { H H } \\
\text { H. H } \\
\text { H H }\end{array}$ \\
\hline
\end{tabular}

Figura 5. Fotografia da tabela original de comparação das combinações do gás olefiante com os sais de amônio. Dumas, J.-B.; Boullay, P.; Mémoire sur les ethers composés. Annales de Chimie et de Physique 1828, 37, 49 e 50, em http//www.books.google.com.br, acessada em Janeiro 2010

\section{CONCLUSÃO}

A lei de volumes associada ao método da densidade de vapor permitiu converter a composição em peso de uma substância para a composição em volumes. Essa conversão gerava uma fórmula empírica que não era suficiente para identificar um composto orgânico, sobretudo diante dos muitos casos de isomeria na Química Orgânica. Todavia, expressar a composição em volumes possibilitava uma interpretação em termos de átomos no contexto da teoria de Berzelius. Esses átomos ou volumes poderiam constituir grupos, de modo a tornarem-se um constituinte imediato comum a muitas substâncias ao integrarem moléculas mais complexas, a exemplo da Química Inorgânica. Não era sempre possível observar diretamente os constituintes imediatos de um composto, mas era possível desmembrar as fórmulas empíricas em grupos conhecidos de compostos mais simples e reuni-los em uma fórmula de constituição binária, como se pode observar na tabela de classificação de Dumas e Boullay de 1828. A lei de Gay-Lussac e seu trabalho com as densidades de vapor, juntamente com as fórmulas de Berzelius tornaram possível a primeira classificação dos compostos orgânicos baseada no conhecimento da composição e da constituição dos compostos orgânicos, investigadas por meio de experimentos e da construção de modelos de fórmulas no papel e não nos critérios puramente taxonômicos da História Natural.

Alguns anos mais tarde, Liebig, Friedrich Wöhler (1800-1882) e Berzelius seguiram este exemplo construindo uma nova classe de substâncias orgânicas. Em 1840, Auguste Laurent (1807-1853) e Charles Fréderic Gerhardt (1816-1856) desenvolveram um novo sistema de classificação mais adequado, seguindo-se o de Friedrich August Kekulé (1829-1896), que priorizou a relação entre a constituição invisível de um composto orgânico, representada por um modelo de fórmula e suas propriedades observáveis e mensuráveis. Substâncias com uma fórmula básica comum e com propriedades químicas semelhantes eram reunidas em séries homólogas.

\section{REFERÊNCIAS E NOTAS}

1. Hobsbawm, E. J.; A Era das Revoluções 1789-1848, Paz e Terra: São Paulo, 1977, p. 385.

2. Crosland, M.; Gay-Lussac savant et Bourgeois, Éditions Belin: Paris, 1991, p. 25.

3. Crosland, op. cit., p. 30.

4. Crosland, op. cit., p. 41.

5. Crosland, op. cit., p. 57.

6. Crosland, op. cit., p. 46.

7. Filgueiras, C. A. L.; Química Nova na Escola 2004, n. 20, 38; Crosland, M., op. cit., 50.

8. Eudiômetro é um instrumento usado para determinar a quantidade de oxigênio no ar, por meio da reação deste com o hidrogênio usando uma faísca. Além do eudiômetro, Volta construiu a primeira pilha em 1800, após Luigi Galvani (1737-1798) divulgar os resultados sobre suas experiências com descargas elétricas em corpos de rãs mortas. Galvani concluíra pela existência de um fluido elétrico animal. O debate a respeito da eletricidade animal foi intenso e impulsionou a construção de novos experimentos para refutar ou corroborar a explicação de Galvani. Volta se empenhou para construir experimentos que demonstrassem que a eletricidade manifestada era do mesmo tipo daquela produzida pelas máquinas eletrostáticas. Concluiu que dois metais distintos em contato funcionavam como uma fonte de eletricidade e que as contrações observadas por Galvani no corpo da rã eram provocadas pelo fato do corpo conduzir o fluido elétrico. Desejando aumentar a produção de eletricidade obtida, empilhou discos de dois metais distintos, colocando entre eles um papel umedecido em solução ácida. Com esse artefato, 
obteve uma faísca ao colocar em contato as duas extremidades da pilha usando um fio. As pilhas foram rapidamente incorporadas à rotina dos laboratórios pelos pesquisadores da época, pois permitiam a observação de fenômenos dificilmente observados antes da sua construção. $\mathrm{Na}$ Química, um de seus empregos favoritos foi na eletrólise, um método de decomposição de substâncias que foi aperfeiçoado com a utilização das mesmas.

9. Crosland, M. ; op. cit., p. 142. Esse tipo de análise era muito criticado pelos boticários por destruir os "princípios imediatos" extraídos de plantas e animais. Esses princípios eram empregados em tinturas, medicamentos, perfumaria, sabão e para curtir o couro.

10. Crosland, op. cit., p. 55.

11. Em termos modernos, segue-se que a energia interna de um gás ideal depende apenas da temperatura.

12. A Société Philomathique foi fundada antes da Revolução, composta por membros eleitos, permitiu a troca entre os pesquisadores durante o período no qual a Académie des Sciences foi suprimida. Muito ativa nos anos 1800, a Sociedade se mantinha informada de tudo que se passava nas instituições de pesquisa, acolhia os jovens pesquisadores para apresentar seus trabalhos, imprimia suas contribuições e possibilitava que se tornassem conhecidos. Thenard, indicado por Vauquelin, foi eleito membro após seu mestre ter apresentado seu trabalho sobre o acetato de chumbo em 18/06/1803. Gay-Lussac, indicado por Berhollet, passou a fazer parte dessa sociedade em 26/03/1805. O binômio GayLussac - Thenard foi muito ativo na Sociedade durante essa primeira década, na qual seus nomes se encontravam frequentemente associados. Juntamente com a apresentação de trabalhos, os dois pesquisadores colaboraram no Nouveau Bulletin des Sciences, relançado em 1807, pela Société Philomathique de Paris. Gay-Lussac fazia parte da comissão para a seção de Física e Thenard da comissão para a seção de Química mineral e vegetal. Exatamente à mesma época, os dois pesquisadores se reencontravam em outro círculo: a Société d'Arcueil, cujo papel foi essencial sob o Primeiro Império. Thenard só passou a fazer parte da Société d'Arcueil em 1804, após sua nomeação para o Collège de France para substituir Vauquelin. Com a sua saída, Thenard deixou vago o cargo de preparador de Química na École Polytechnique, que foi ocupado por Gay-Lussac. Os dois voltaram a se encontrar como professores na Ècole Polytechnique: Gay-Lussac foi professor de Química de 1804 a 1840 e Thenard após o período de 1797 a 1804 , retornou em 1810 permanecendo até 1836. A aliança entre as duas disciplinas, Química e Física, como desejava Berthollet, se instaurou com o binômio Gay-Lussac e Thenard, o que possibilitou empreender as famosas pesquisas físico-químicas. Nas palavras do filho de Thenard "foi na Société d'Arcueil que Gay-Lussac e Thenard aprenderam a se conhecer e a se apreciar; foi sob os auspícios de Berthollet e de Laplace que se formou essa associação de dois amigos". Acrescenta-se que o binômio também marcou presença na Faculté des Sciences de Paris e no Institut, mais uma vez, Gay-Lussac como professor de Física e Thenard como professor de Química, cada qual com uma abordagem própria em relação à pesquisa científica. Emptoz, G.; Bulletin de la Société des Amis de La Bibliothèque et de l' Histoire de École poytechnique 2012, 50, 31.

13. Gay-Lussac, J-L.; Sur la combinaison des substances gazeuses, les unes avec les autres. Mémoires de la Société de physique et de chimie de la Société d'Arcueil 1809, 2, 208, em http://www.bibnum.education.fr, acessada em Março 2013.

14. Fórmulas das substâncias à época.

15. Gay-Lussac, op. cit., p. 218.

16. Durante a primeira metade do século XIX e até mais adiante, há uma confusão quanto à terminologia e à notação empregada. Átomo físico, átomo químico, molécula eram termos que possuíam significados diferentes. Os equivalentes eram vistos como quantidades empíricas e estavam mais de acordo com a filosofia positivista. Átomo físico se refere à partícula indivisível, como o átomo de Dalton. Átomo químico se refere à menor quantidade de um corpo simples que pode participar de uma reação química e molécula à menor quantidade uma substância que é necessária empregar em uma reação química. Pesos equivalentes correspondem às quantidades em massa que expressam a menor proporção em massa entre substâncias que reagem. Entre os "atomistas", é possível ainda distinguir dois subgrupos: os verdadeiros atomistas para os quais o átomo tem uma existência real e os atomistas pragmáticos, para os quais o átomo é um artifício lógico ou uma hipótese de trabalho. Durante todo o século XIX, não houve consenso sobre a hipótese atômica entre os químicos.

17. Berthollet acreditava que a afinidade química era uma força semelhante à gravidade. Concebia qualquer tipo de combinação entre substâncias como uma expressão dessa mesma força, porém a afinidade era apenas um fator entre outros que influenciavam a reação. A combinação variava com as condições físicas do experimento e a composição de uma substância era, portanto, variável. Proust que defendia a ideia de composição definida (lei das proporções definidas, 1799) se envolveu em uma famosa controvérsia com Berthollet, que durou de 1801 a 1807.

18. Gay-Lussac, op. cit., p. 232.

19. Thomson, T., 1809 citado por Rocke, A. J.; Chemical Atomism in the Nineteenth Century From Dalton to Cannizzaro, State University Press: Ohio, 1984, p. 41.

20. Dalton criticou a aproximação de 1,97 para 2 feita por Gay-Lussac para a proporção em volumes de hidrogênio e oxigênio que se combinam para formar a água. Rocke, A., op.cit., p. 42. A primeira teoria recebeu muitas críticas e esbarrou em algumas contradições experimentais como, por exemplo, a questão da difusão dos gases. Considerando que um gás se comportava como um vácuo para o outro, a difusão deveria ser um processo espontâneo e rápido, o que não era verificado experimentalmente. A objeção mais séria à Teoria da Mistura de Gases era a visão de que o ar atmosférico era um composto químico e não uma mistura de nitrogênio e oxigênio. Isso foi sustentado por F. Humboldt, Morozzo, por Davy inicialmente, e ainda por Berthollet, Bostock, Murray, Gough e Thomas Thomson.

21. Meldrum, A. N., 1906 citado por Partington, J. R.; A History of Chemistry, Macmillan: Londres, 1962, vol. 3, p. 778.

22. Dalton, J.; A New System of Chemical Philosophy, Manchester: [s.n.], 1, 1808-1810, p. 188, em http://www.archive.org, acessada em Março 2013. O segundo volume foi publicado em 1827.

23. Dalton, J.; op. cit., p. 189; Rocke, A.; op. cit., p. 33.

24. Rocke, A. J.; Social Research: An International Quarterly 2005, vol. 72, em http://www.jstor.org, acessada em Março 2013.

25. Rocke, A.; 1984, op. cit., p. 12.

26. Kekulé, A.; On some points of chemical philosophy, The Laboratory 1867, I, 304.

27. Relação que ficou conhecida como Hipótese de Avogadro.

28. O gás olefiante corresponde a eteno, cuja fórmula é $\mathrm{C}_{2} \mathrm{H}_{4}$ e a proporção em massa correta é 1:6. Saussure, em 1811, apresentou os resultados em proporção em peso ao invés de percentagem. Klein, U.; Cultures of Organic Chemistry In The Nineteenth Century, University Press: Stanford, 2003, p. 111.

29. Saussure, T., 1814 citado por Klein, U., op. cit., p. 112.

30. Dalton, J., 1819 citado por Partington, J. R.; A History of Chemistry, Macmillan: Londres, 1964, vol. 4, p. 342.

31. Gay-Lussac, 1815 citado por Klein, op. cit., p. 114.

32. Gay-Lussac, op. cit., p. 219. A correspondência atual é óxido carbônico com monóxido de carbono - $\mathrm{CO}$ e ácido carbônico com dióxido de carbono - $\mathrm{CO}_{2}$. Adotando a fórmula $\mathrm{C}^{2} \mathrm{O}$, o peso atômico do carbono será 6 em uma escala de $\mathrm{H}=1$ e $\mathrm{O}=16$.

33. Berzelius, J. J.; Essay on the cause of chemical proportions, and on some circumstances relating to them: together with a short and easy method of expressing them, Annals of Philosophy 1813, 2. 443-454, 450, em http// www.books.google.com.br, acessada em Março 2013. 
34. Nessas fórmulas, os índices, que atualmente indicam o número de átomos de um determinado elemento e escritos como inferiores, eram representados como superiores. Liebig, em 1834, foi quem mudou a posição dos índices. Partington, J. R.; 1964, op. cit., p. 158.

35. Berzelius, J. J.; Essay on the cause of chemical proportions, and on some circumstances relating to them: together with a short and easy method of expressing them, Annals of Philosophy 1814, 3, 52, em http//www. books.google.com.br, acessada em Março 2013.

36. Klein, U.; op.cit., p. 9.

37. Crosland, M.; Historical Studies in the Language of Chemistry, Heinemannn Educational Books: Londres, 1962, p. 319.

38. Berzelius, J. J. ; Essai sur les proportions déterminées dans lesquelles se trouvent réunis les élémens de la nature organique, Annales de chimie, Paris, 1814, 92, 143, em http//www.books.google.com.br, acessada em Março 2013.

39. Rocke, A.; 1984, op. cit., p. 111.

40. Rocke, A.; 1984, op. cit., p. 42.

41. O artigo Sur l'acide des prussiates triples, (Annales de Chimie et de Physique 1823, 22, 320) foi o primeiro artigo de Gay-Lussac publicado após a morte de Berthollet em 1822.

42. Gay-Lussac, 1824 citado por Rocke, A.; 1984, op. cit., p. 112. Analyse du fulminate d'argent., Annales de Chimie et de Physique 1824, 25, 285.

43. Dumas, J.-B.; Mémoire sur quelques points de la théorie atomistique, Annales de Chimie et Physique 1826, 33, 338.

44. Rocke, A.; 1984, op. cit., p. 115.

45. Dumas, J.-B.; 1826, op. cit., p. 338.

46. Rocke, A.; 1984, op. cit., p. 112.

47. O óleo doce de vinho é, provavelmente, o sulfato de etila: $\left(\mathrm{C}_{2} \mathrm{H}_{5}\right)_{2} \mathrm{SO}_{4}$.

48. Ácido que resulta da ação do ácido sulfúrico sobre o álcool comum na formação do éter etílico, correspondia a $\mathrm{C}^{4} \mathrm{H}^{8} \mathrm{O} \cdot 2 \mathrm{SO}^{3}+\mathrm{OH}$ e o óleo doce de vinho correspondia ao gás olefiante - $\mathrm{C}^{2} \mathrm{H}^{2}$, em fórmulas atuais temos $\mathrm{C}_{2} \mathrm{H}_{5} \mathrm{O} . \mathrm{SO}_{3} \mathrm{H}_{\text {e }} \mathrm{C}_{2} \mathrm{H}_{4}$; Regnault, V.; Cours élémentaire de chimie à l'usage des facultés, des établissements secondaire, des écoles normales et des écoles industrielles, Masson: Paris, 1854, vol. IV, em http:// archive.org, acessada em Março 2013.

49. Dumas, J.-B.; Boullay, P. ; Mémoire sur la formation de l'ether sulfurique, Annales de Chimie et de Physique 1827, 36, 294, em http//www. iris.univ-lille1.fr, acessada em Janeiro 2010.

50. Dumas, J.-B.; Boullay, P.; 1827, op. cit., 309.

51. O oxigênio está representado por um ponto suspenso entre os hidrogênios.

52. Éter do ácido acético se refere ao éster etanoato de etila, cuja fórmula atual é $\mathrm{C}_{4} \mathrm{H}_{8} \mathrm{O}_{2}$. O nome geral éter foi introduzido em 1787, por Guyton de Morveau no seu Méthode de Nomenclature Chimique, para compostos resultantes da reação do álcool com ácidos. O nome éster foi adotado por L. Gmelin em 1848 e Schlossberger em 1850. Partington, J. R.; 1964, op. cit., p. 342.

53. Klein, U.; op. cit., p. 138.

54. Esta fórmula apresenta o dobro de volumes de carbono em relação à fórmula deduzida por Berzelius, visto que os franceses adotaram a densidade 0,41, calculada por Gay-Lussac, correspondente ao peso 6 .

55. Dumas, J.-B.; Boullay, P.; Mémoire sur les ethers composés, Annales de Chimie et de Physique 1828, 37, 31, em http//www.books.google.com. br, acessada em Março 2013.

56. Klein, U.; op. cit., p. 139.

57. O terceiro grupo corresponde atualmente à classe dos ésteres.

58. Dumas, J.-B.; Boullay, P.; 1828, op. cit., p. 43.

59. Klein, U.; op. cit., p. 139. Nos anos 1820, as fórmulas de Berzelius foram aplicadas pelos químicos a toda Química Orgânica como "ferramentas no papel" para a construção de modelos interpretativos das reações químicas orgânicas, obedecendo a um esquema de balanceamento e incorporando, inclusive, suposições adicionais como, por exemplo, uma constituição binária dos compostos aos modos da Química Inorgânica. A manipulação das fórmulas berzelianas no papel permitia o arranjo dos elementos em grupos conhecidos, algumas vezes experimentalmente, como no caso do gás olefiante. Nesse caso havia uma correspondência entre a representação e um produto obtido no experimento, o que incentivou o uso de tais ferramentas para modelar a constituição dos compostos orgânicos e posteriormente para construir novas taxonomias. Esse procedimento sugere algumas questões como, por exemplo : Que manipulações eram permitidas, o que tinha significado químico e o que não tinha? O conceito geral de uma constituição binária, assim como a construção de analogias mais específicas determinavam, então, o que era ou não permitido nas manipulações das fórmulas. O sentido de tais manipulações resultava do significado contemporâneo do conceito de constituição binária, que foi contruído em uma prática experimental lidando com substâncias macroscópicas.

60. Thomson, T.; System of Chemistry 1817, vol. 2, p. 348, em http://books. google.com.br, acessada em Março 2013.

61. Compostos isomórficos são aqueles que possuem composição química semelhante, portanto fórmulas análogas e formas cristalinas idênticas. Esse tipo de fenômeno foi identificado por Eilhard Mitscherlich (17941863) em 1818 ao estudar fosfatos e arseniatos. Compostos isômeros são compostos que possuem a mesma composição e propriedades diferentes. Berzelius assim os denominou, em 1831, após o fenômeno já ter sido observado por ele e outros, como Gay-Lussac, Dalton, Chevreul, Liebig, Wohler...

62. Fisher, N. W.; Ambix 1973, 20, 111.

63. Dumas, J.-B.; Boullay P.; 1828, op. cit., p. 52.

64. Az é o símbolo antigo para o azoto, mais tarde substituído por $\mathrm{N}$. 